\title{
The inhibition of the mammalian DNA methyltransferase 3a (Dnmt3a) by dietary black tea and coffee polyphenols
}

\author{
Arumugam Rajavelu², Zumrad Tulyasheva ${ }^{3}$, Rakesh Jaiswal ${ }^{1}$, Albert Jeltsch ${ }^{2^{*}}$ and Nikolai Kuhnert ${ }^{1 *}$
}

\begin{abstract}
Background: Black tea is, second only to water, the most consumed beverage globally. Previously, the inhibition of DNA methyltransferase 1 was shown by dietary polyphenols and epi-gallocatechin gallate (EGCG), the main polyphenolic constituent of green tea, and 5-caffeoyl quinic acid, the main phenolic constituent of the green coffee bean.

Results: We studied the inhibition of DNA methyltransferase 3a by a series of dietary polyphenols from black tea such as theaflavins and thearubigins and chlorogenic acid derivatives from coffee. For theaflavin 3,3 digallate and thearubigins $I C_{50}$ values in the lower micro molar range were observed, which when compared to pharmacokinetic data available, suggest an effect of physiological relevance.

Conclusions: Since Dnnmt3a has been associated with development, cancer and brain function, these data suggest a biochemical mechanism for the beneficial health effect of black tea and coffee and a possible molecular mechanism for the improvement of brain performance and mental health by dietary polyphenols.
\end{abstract}

\section{Background}

Black tea is, second only to water, the most consumed beverage globally with an average per capita consumption of around $550 \mathrm{ml}$ per day. The annual production of tea leaves reached a record high in 2008 with a global harvest of 3.75. Mt [1]. Production of dried tea comprises $20 \%$ green, $2 \%$ oolong and the remainder black. Following black tea, coffee is the third most consumed beverage globally with an annual production of $9.7 \mathrm{Mt}$ and a daily consumption of around $300 \mathrm{ml}$ (data from http://www.fas.usda.gov/, obtained 1st March 2011). Strong epidemiological evidence has repeatedly linked the consumption both black tea [2] and coffee [3,4] to a variety of beneficial health effects, among them is the prevention of multifactorial diseases including cancer, cardiovascular disease and neurological disorders as well as a series of psychoactive responses improving

\footnotetext{
* Correspondence: a.jeltsch@jacobs-university.de; n.kuhnert@jacobs-university. de

'Chemistry, Jacobs University Bremen, Campus Ring 1, 28759 Bremen, Germany

${ }^{2}$ Biochemistry, Jacobs University Bremen, Campus Ring 1, 28759 Bremen, Germany

Full list of author information is available at the end of the article
}

alertness, mood and general mental performance [5-8]. Recently, Unilever made an application for a health claim, in which the black tea beverage should supposedly improve mental alertness and focus, based on studies by Nurk et al. with the activities of the two compounds caffeine and L-theanine as the proposed rationale [9]. While epidemiological studies link two causally unrelated events, e. g. a beneficial health effect with the consumption of a certain diet, with a certain statistical probability, the molecular causes of these epidemiological observations are rarely known. In order to rationalize epidemiological observations, a biological target must be identified that is mechanistically linked to the beneficial health effect reported, as well as the specific molecules contained in the diet that interact with the biological target in question at dietary and physiologically relevant concentrations. The search for such matching pairs of biological targets and dietary compound must be considered an exercise of fishing in the dark, however, where enzymes known to be intimately involved in the area in question need to be systematically screened against secondary metabolites known to be produced by the dietary plant in question.
C Biomed Central

() 2011 Rajavelu et al; licensee BioMed Central Ltd. This is an Open Access article distributed under the terms of the Creative Commons Attribution License (http://creativecommons.org/licenses/by/2.0), which permits unrestricted use, distribution, and reproduction in any medium, provided the original work is properly cited. 
Prompted by reports of Fang and co-workers, who have recently reported the inhibition of DNA methyltransferase 1 (Dnmt1) by a series of dietary polyphenols [10] and work by Lee and co-workers on the inhibition of the same enzyme investigating most notably epi-gallocatechin gallate (EGCG) [11] (the main polyphenolic constituent of green tea) and 5-caffeoyl quinic acid [12] (the main phenolic constituent of the green coffee bean), and Nandakumar, showing the reduction of cellular DNA methylation after admission of (-)-epigallocatechin-3-gallate [13], we decided to screen the interaction of a series of black tea and coffee polyphenols against DNA methyltransferase 3a, another important member of this family of enzymes.

DNA methyltransferases catalyzes methylation of DNA at cytosine residues and play an important role in epigenetic regulation of gene expression, $\mathrm{X}$-chromosome inactivation, genomic imprinting, and development cellular aging and cell differentiation [14,15]. In mammals, DNA methylation is catalyzed mainly by three DNA methyltransferases [15,16]: Dnmt1, Dnmt3a, and Dnmt3b. Dnmt1 has a high preference for hemimethylated DNA and is essential for maintaining the methylation patterns during each round of DNA replication. On the other hand, Dnmt3a and Dnmt3b modify both unmethylated and hemimethylated DNA and are responsible for de novo methylation during early development. Errors in DNA methylation contribute to both the initiation and the progression of various cancers $[17,18]$. In addition, aberrant or missing DNA methylation causes many kinds of diseases which include defects in embryonic development or brain development and neurological defects which are also associated with behavioral changes [19]. Hypermethylation of genes is one of important process in cancer development, typically resulting in the repression of tumor suppressor genes. Preventing the hypermethylation of promoter genes by selective inhibition of methyltransferases could pave a way for cancer treatment [20-22]. Importantly it has been shown that upon use of methyltransferase inhibitors it was possible to reactivate gene silenced by promoter methylation in cancers and thus modulate gene expression. Several efforts are directed at developing small molecules that target DNA methyltransferases and other elements of the machinery, as the proteins that bind to methylated $\mathrm{CpG}$; some are in clinical trials [20-22].

Another important issue of DNA methylation is its function in brain development. Levenson and coworkers showed that Dnmt1 is involved in the formation of hippocampus-dependent long term memory [23]. They found that the promoters for reelin and brain-derived neurotrophic factor (genes implicated in the induction of synaptic plasticity in the adult hippocampus) exhibit rapid and dramatic changes in cytosine methylation when Dnmt1 activity was inhibited. Moreover, DNA methyltransferase inhibitors like 5-aza-2-deoxycytidine blocked the induction of long term potentiation at Schaffer collateral synapses. Furthermore, Dnmt3adependent DNA methylation has been reported to influence transcription of neurogenic genes [24]. Additional studies showed that Dnmt1 and Dnmt3a regulate synaptic function in adult forebrain neurons [25] and Dnmt3a affects plasticity of neurons [26].

Changes in the DNA methylation pattern of regions in the hippocampus are associated with behavioral changes in rat [27]. In addition, Dnmt3a has been recently shown to affect the emotional behaviour [26]. Thus, DNA methylation which is already known to be involved in setting up cellular memory is also involved in brain function. The combination of studies in cell lines and in animal models, coupled with data obtained from post-mortem human material provides compelling evidence that aberrant methylation may contribute to psychiatric diseases like schizophrenia and psychosis [28]. Strong epidemiological evidence suggests that particularly for black tea and green tea there is an inverse relation between intake and significant beneficial effects on patients suffering from psychological disorders [2,5-8]. Currently, no accepted rationale on the molecular level exists that can account for these epidemiological findings. Dnmts are a possible biological target for tea dietary polyphenols suggesting a molecular based rationale for the observed biological activities.

\section{Results}

\section{Expression and purification of Dnmt3a-C}

The catalytic domain of Dnmt3a was expressed and purified following an established protocol $[29,30]$. The purified protein by Ni-NTA affinity chromatography was $>90 \%$ homogenous as judged from SDS-PAGE stained with colloidal Coomassie Blue (Figure 1).

\section{Selection and purification of black tea and coffee polyphenols}

Black tea is produced from the young green shoots of the tea plant (Camellia sinensis), which are converted to black tea by fermentation [31]. There are two major processes, the 'orthodox' and the 'cut-tear-curl'. In both, the objective is to achieve efficient disruption of the cellular substructure bringing phenolic compounds present in the green tea leaf, mainly flavan-3-ols otherwise known as catechins, into contact with polyphenol oxidases and activating many other enzymes. The catechin substrates are oxidized and extensively transformed into novel dimeric, oligomeric and polymeric compounds. The chemical composition of black tea brew can be divided into (i) a series of well characterized small 


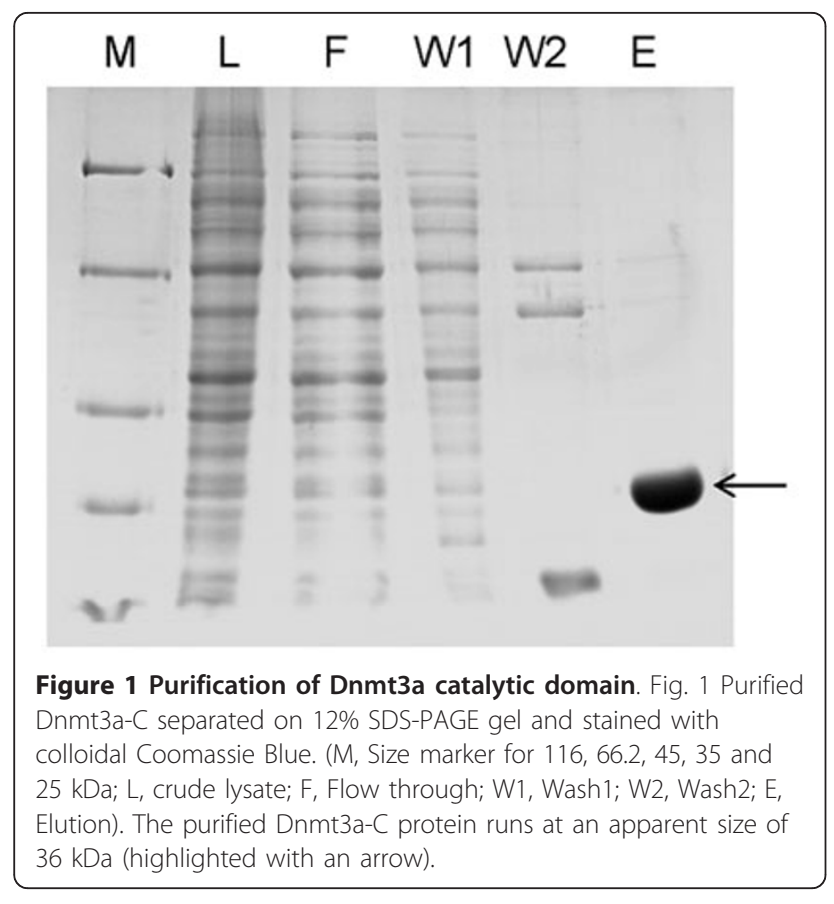

molecules including alkaloids (e.g. theobromine and caffeine), carbohydrates and amino acids (including theanine), and a series of glycosylated flavonoids and dimers of catechins including most notably theaflavins together accounting for $30-40 \%$ of the dry mass of a typical black tea infusion, and (ii) the heterogeneous and poorly characterized polyphenolic fermentation products accounting for the remaining $60-70 \%$ [31]. This material was originally referred to as oxytheotannin and later renamed by Roberts as thearubigins [32].

For this study, we first selected EGCG N1 and (-)-epigallocatechin N4 (from green tea, also on occasions found in black tea at low concentrations) as reference compounds. Next we selected the four most common theaflavin derivatives: theaflavin $\mathbf{N 2}$, theaflavin-3-gallate $\mathbf{N 5}$, theaflavin 3'-gallate $\mathbf{N 3}$ and theaflavin 3, 3'-digallate N6 (see Figure 2) [33,34]. All four compounds are found in black tea infusions at concentrations of around $100 \mathrm{mM}$, making up $2-3 \%$ of the total content of dry mass in typical black tea infusion. Theaflavins are structurally closely related the catechins being formal dimers of EGCG obtained through a two electron oxidation followed by $\mathrm{C}-\mathrm{C}$ bond formation and a benzylic acid type rearrangement leading to the benztropololone core structure. Next to theaflavins we decided to screen as well two crude thearubigin fractions. We recently proposed that thearubigins contain several thousands polyhydroxylated theaflavin derivatives in equilibrium with their ortho-quinones. Theaflavins were obtained by extraction from black tea infusion followed by purification by preparative HPLC. The purity was assessed by
LC-tandem MS. Thearubigins were obtained from black tea infusions using a protocol developed by Roberts [35].

For coffee polyphenols, we selected a range of naturally occurring and synthetic derivatives of chlorogenic acids. Chlorogenic acids (CGAs) are formally hydroxylcinnamate esters of quinic acid with a dietary intake of an estimated 2 g per human per day [36]. We recently reported a total of 70 different chlorogenic acids found in green coffee beans and selected some representative examples containing both caffeic acid and ferulic acid substituents [37-40]. Furthermore, we selected a range of epimers of CGAs produced from the original secondary plant metabolites by roasting of the coffee beans. Representative structures are shown in Figure 2. All CGA derivatives were obtained through chemical synthesis unless stated otherwise.

\section{Dnmt3a-C activity and inhibitors screening}

The purified Dnmt3a-C was catalytically highly active (Figure 3). For an initial screening of the twenty four inhibitor candidates, Dnmt3a-C DNA methylation kinetics were carried out in the presence of $100 \mu \mathrm{M}$ of compound. Rates of DNA methylation were derived by linear regression of the initial phase of the reaction progress curves. The reaction rates were compared with control reactions carried out after addition of a corresponding volume of DMSO to ensure identical reaction conditions, because DMSO had been shown before to influence the activity of Dnmt3a [41]. As shown in Figure 4, four of the compounds had a substantial inhibitory effect for the in vitro Dnmt3a-C activity (N6-N8 and N12). To determine $\mathrm{IC}_{50}$ values, DNA methylation kinetics were carried out in the presence of variable concentrations of the inhibitors, initial slopes derived and the activity profile analysed by fitting of the experimental data to the equation:

$$
\mathrm{A}\left(\mathrm{C}_{\mathrm{I}}\right)=\mathrm{A}_{0} \times \mathrm{C}_{\mathrm{I}} /\left(\mathrm{IC}_{50}+\mathrm{C}_{\mathrm{I}}\right)+\mathrm{BL}
$$

with: $c_{I}$, concentration of the inhibitor; $A\left(c_{I}\right)$, activity in presence of inhibitor at concentration $\mathrm{c} ; \mathrm{A}_{0}$, activity in absence of inhibitor; BL, baseline.

As shown in Figure 5, the $\mathrm{IC}_{50}$ values for the compounds N6-N8 and N12 were all in the lower $\mu \mathrm{M}$ range.

\section{Discussion}

Lee et al had showed that caffeic acid and chlorogenic acid inhibit the activity of M.SssI and Dnmt1 and decrease the methylation level at the RAR beta promoter gene in the breast cancer cell lines [12]. Furthermore, they have recently described the inhibition of human Dnmt1 by tea flavanoids such as EGCG, catechin and other flavanoids such as quercitin and myristin, observing $K_{I}$ values in the low micromolar range [11]. While Dnmt1 is considered a biological target involved in 

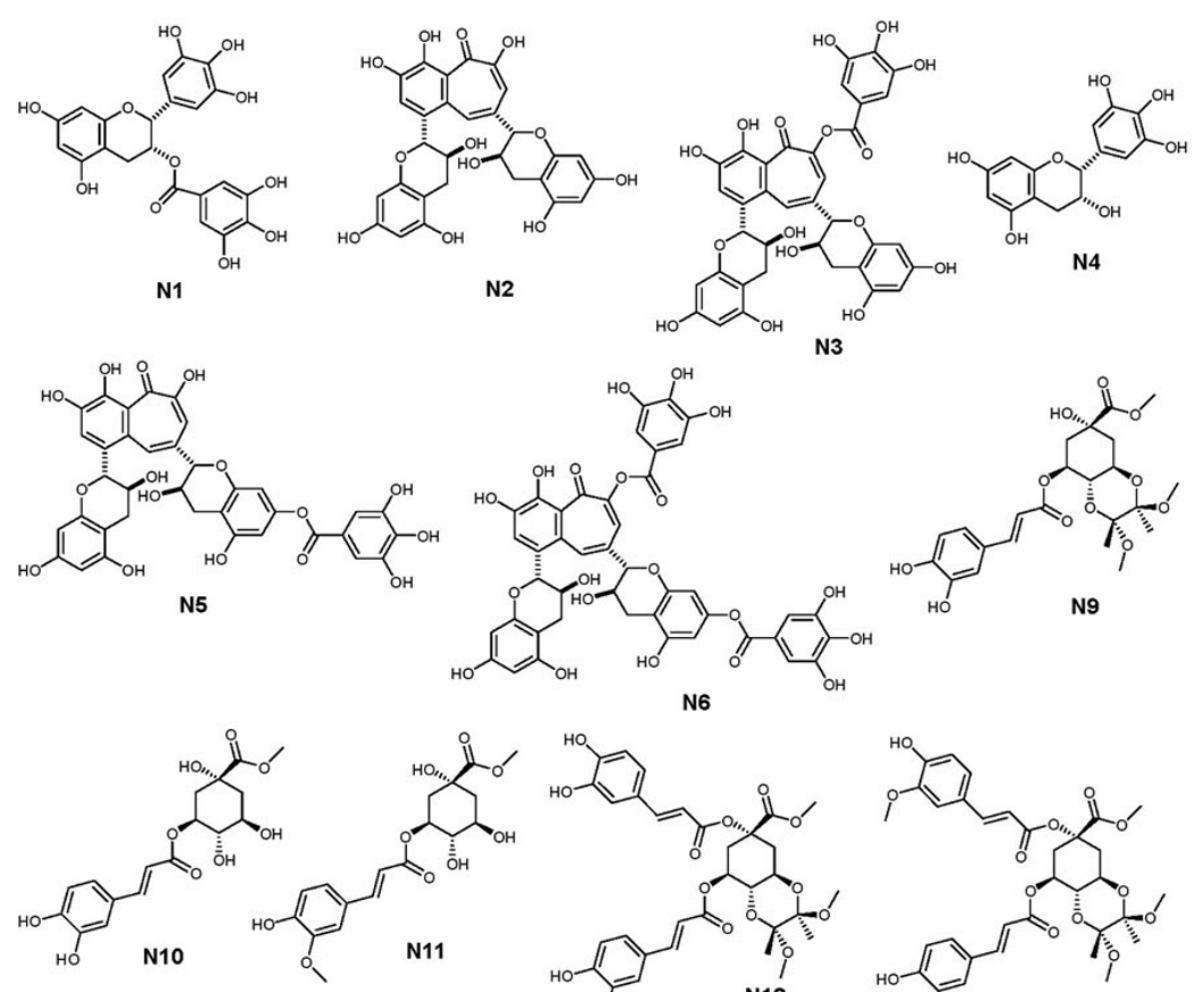

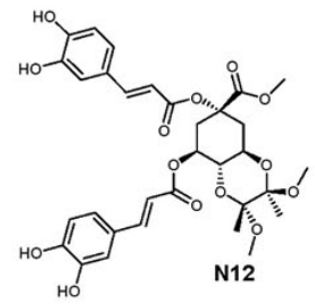

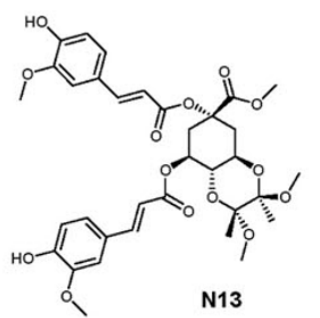

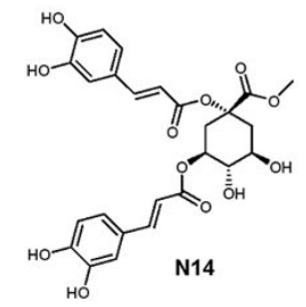

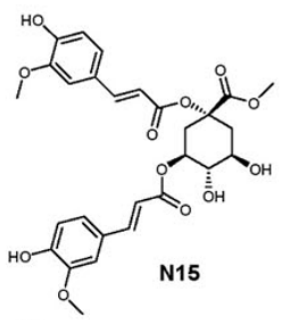

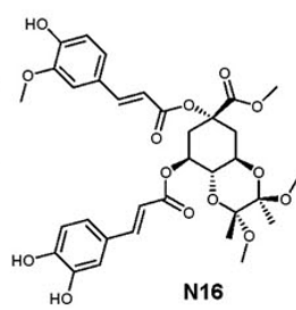<smiles>COC(=O)C(=O)OC(=O)/C=C/c1ccc(O)c(OC)c1</smiles>

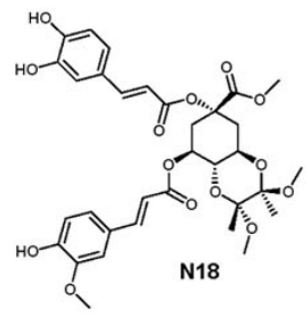

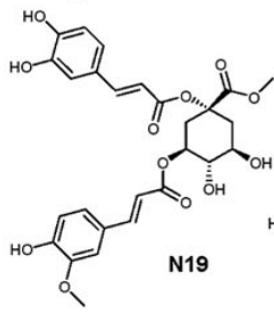

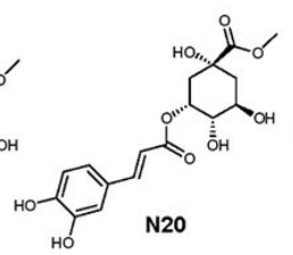

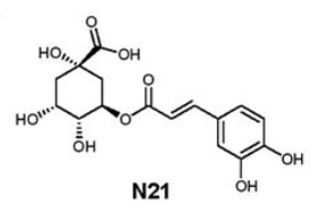<smiles>NC(=O)C=Cc1ccc(O)cc1</smiles>

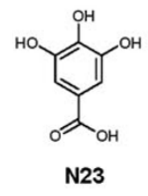

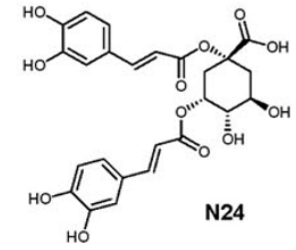

Figure 2 Structures of the compounds tested for Dnmt3a-C inhibition.

cancer development its close relative Dnmt3a, investigated in this study, has been linked to both cancer development and mental performance and health. Therefore, any inhibitory interaction between any of the screened dietary polyphenols and Dnmt3a might allow identification of compounds that have a positive effect on cancer prevention and improved mental performance. 


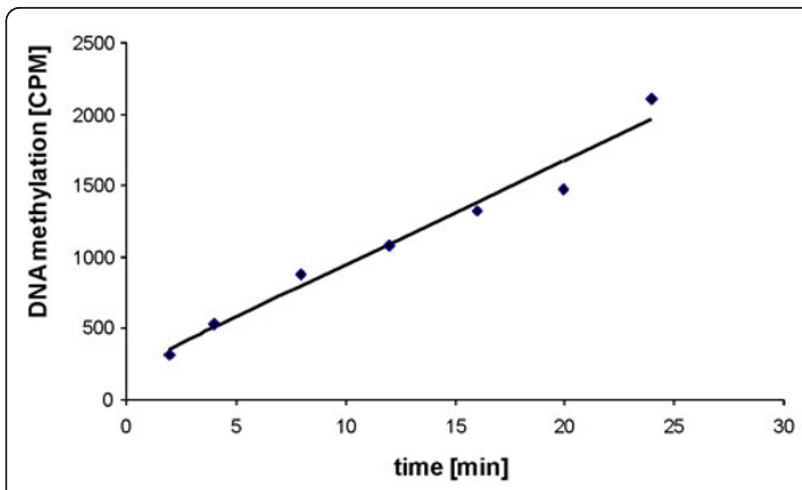

Figure 3 Methyltransferase activity of the purified Dnmt3a-C. Example of the methylation kinetics carried out with purified Dnmt3a-C. Initial slopes were determined by linear regression analysis of the initial linear parts of the reaction progress curves.

\section{Black tea polyphenols}

EGCG (N1) with a reported $\mathrm{IC}_{50}$ on Dnmt1 of $0.21 \mu \mathrm{M}$ and epigallocatechin (N4) showed only weak inhibition of Dnmt3a. A slightly increased activity was observed for theaflavin, theaflavin-3-gallate (N3) and theaflavin 3'gallate (N5) with the gallated derivatives showing a larger inhibitory effect. Theaflavin 3, 3'-digallate (N6) performed best in this series with a measured $\mathrm{IC}_{50}$ value of $44 \mu \mathrm{M}$. Similarly, the thearubigin fractions performed well in this test with $\mathrm{IC}_{50}$ values of $40 \mu \mathrm{M}$ and $28 \mu \mathrm{M}$, respectively (molarity calculated by assuming an average molecular weight of $800 \mathrm{~g} / \mathrm{mol}$ ). It has to be noted that according to our knowledge this is the first time that a thearubigin fraction (consumed at a level of $1 \mathrm{Mt}$ per annum) has been investigated in an enzyme assay and found to exhibit inhibitory activity. Previous work on thearubigins biological activity had focused on interference with signalling cascades in the anti-inflammatory response [42-45]. Due to the structural similarity of theaflavins and thearubigins (poly-hydroxy theaflavins), the inhibition of Dnmt3a does not come as a complete surprise.

To evaluate any possible biological significance of the $\mathrm{IC}_{50}$ values of Dnmt3a inhibition observed here, human pharmacokinetic data need to be consulted. Two published reports address the pharmacokinetic behaviours of theaflavins. Mulder and co-workers report theaflavin concentrations of $4.2{\mu \mathrm{g} \mathrm{l}^{-1}}$ in urine $2 \mathrm{~h}$ after consumption of 1 cup of black tea containing $8.8 \mathrm{mg}$ total theaflavins [46]. Henning reported a concentration of 2 nmol g-1 tissue (if converted around $2 \mu \mathrm{M}$ ) of theaflavin in colon, small intestine, prostate and liver target tissue, with all further three theaflavins N3, N5 and N6 investigated here showing roughly $1 \mu \mathrm{M}$, half this value after consumption of one cup of black tea [47]. Although no plasma concentration values are available for theaflavin derivatives, it can be assumed that the plasma concentration is the same order of magnitude if not even higher when compared with concentrations in target tissues. As the average per capita consumption of black tea is around $550 \mathrm{ml}$ or three cups per day, again a higher physiological concentration must be assumed.

From these data it becomes obvious that out of the compounds investigated theaflavin 3, 3'-digallate N6 is a compound showing reasonable bioavailability. These concentration estimate of $2 \mu \mathrm{M}$ is only roughly by one order of magnitude smaller than the measured $\mathrm{IC}_{50}$ values. Assuming consumption of a black tea beverage rich in theaflavins (a maximum of $50 \mathrm{mg} \mathrm{l}^{-1}$ has been determined) or repeated consumption of larger quantities of black tea the measured $\mathrm{IC}_{50}$ values for Dnmt3a inhibition, therefore, may have biological significance and inhibition of this enzyme can be expected under physiological conditions after black tea consumption. No data are available on thearubigin pharmacokinetics but since a typical cup of tea contains $60-70 \%$ of its dry mass of this mixture of compounds biological significance can as well be assumed.

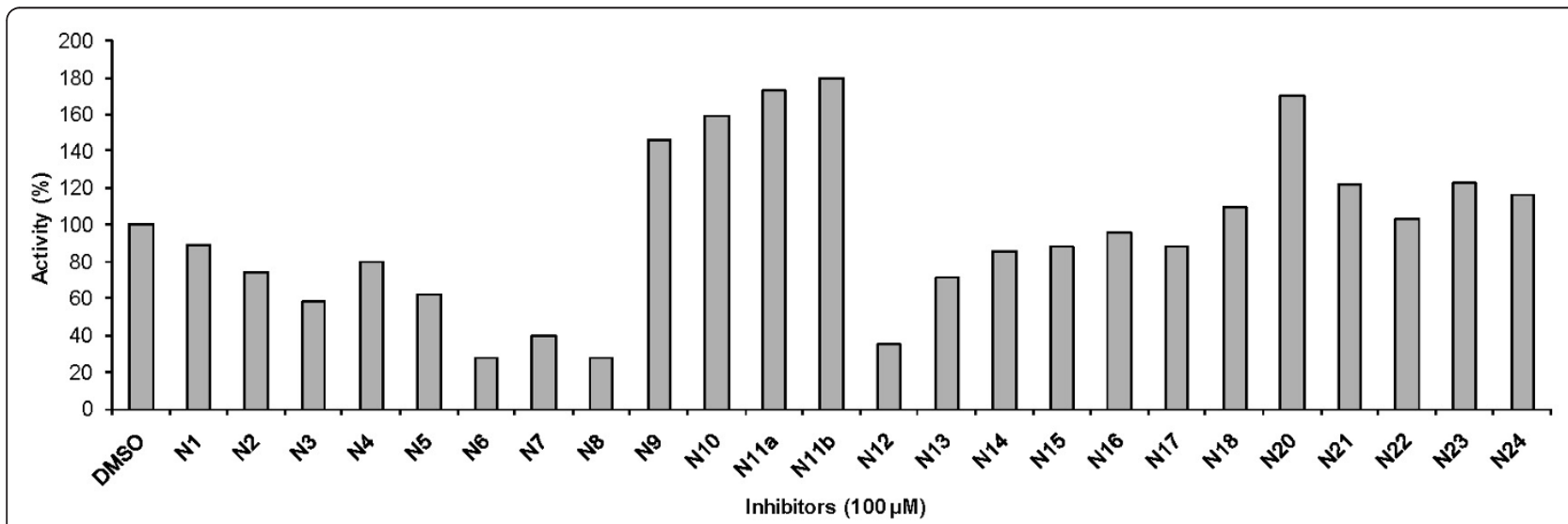

Figure 4 Initial screening of the $\mathbf{2 4}$ compounds for inhibition of Dnmt3a-C. Dnmt3a-C activity was determined in the presence of $100 \mu \mathrm{M}$ compound. The control reaction was performed after adding a corresponding volume of DMSO. 

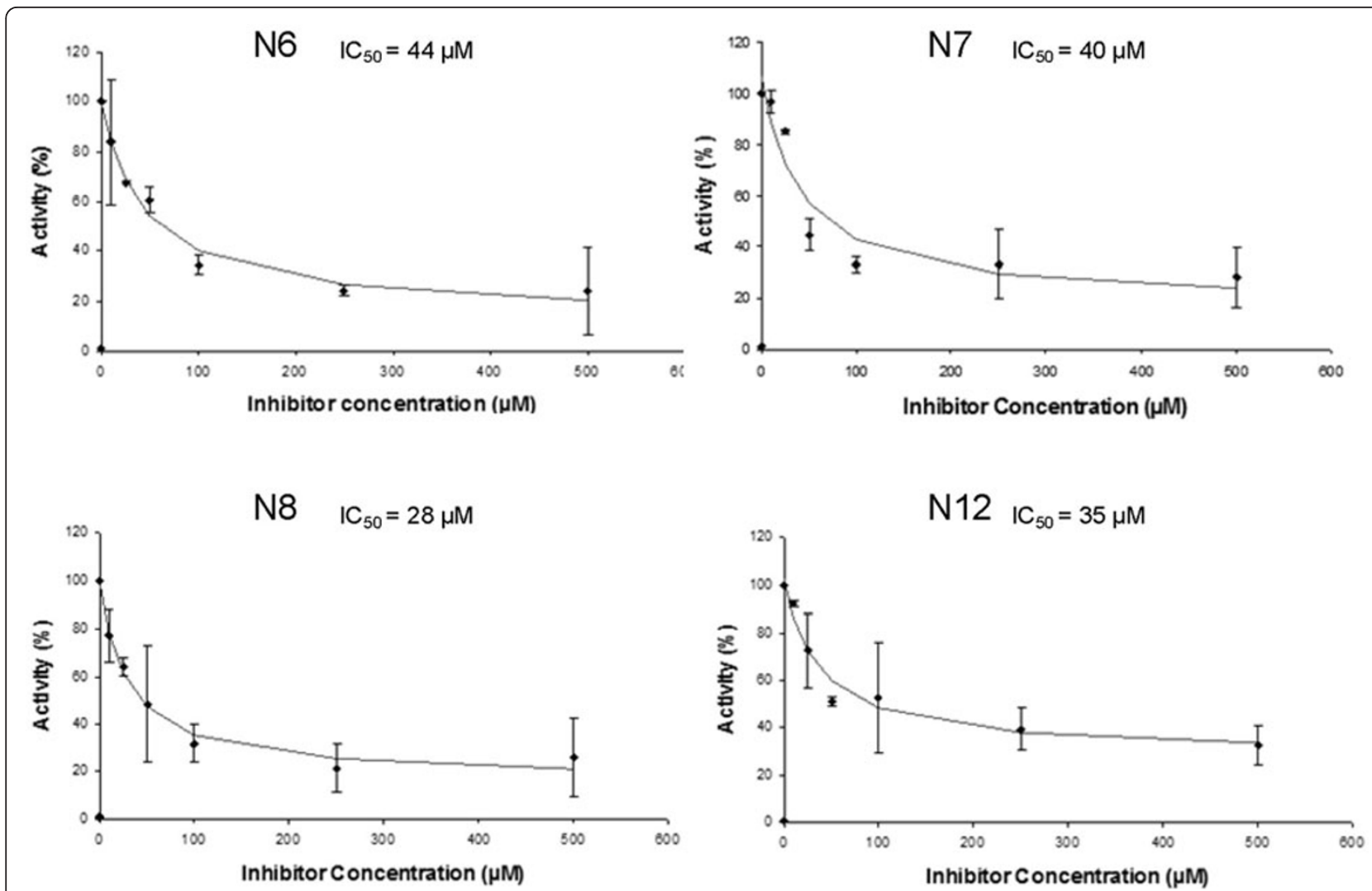

Figure 5 Measurement of IC50 values for compounds N6, N7, N8 and N12. For compounds N6, N7, N8 and N11 DNA methylation kinetics were carried out at different concentration of the compounds to determine the IC50 value. The error bars show the maximal deviations in repeated experiments. IC50 values are valid by $\pm 30 \%$.

Two pieces of further work published recently touch on the problem discussed here and are worth highlighting. Firstly, work by Vauzour et al. showed that dietary polyphenols from berries of similar polarity and structure compared to the polyphenols studied here, are able to cross the blood brain barrier [48], therefore suggesting that brain target tissue could be reached by the compounds under investigation. Secondly, recent work by Müller-Harvey et al. reports an accumulation of tea polyphenols in cell nuclei [49], suggesting that not only target tissue but target cell organelles, in which Dnmt3a methylates DNA can indeed be reached by the compounds under investigation.

\section{Coffee polyphenols}

Out of the twelve chlorogenic acid derivatives screened, seven showed a minor inhibitory effect on Dnmt3a with one compound 1,3-dicaffeoyl-muco-quinic acid diacetal (N12) showing a good $\mathrm{IC}_{50}$ value of $35 \mu \mathrm{M}$. Since compound $\mathrm{N} 12$ is a synthetic derivative, not present in the human diet, this finding has no direct dietary significance. However, the activity of compound N12 clearly indicates that chlorogenic acid derivatives have the potential to inhibit Dnmt3a and this derivative might serve as a lead compound to screen and identify further dietary compound possessing this interesting biological activity.

Interestingly, all compounds showing inhibitory effects are diacyl quinic acids, whereas monoacyl quinic acids showed no effect at all. As a general trend caffeoyl derivatives seem to be more active if compared to feruloyl derivatives and a 1,3-diacyl regiochemistry appears to be favourable. Similarly gallic acid and caffeic acid had no inhibitory effect at all in contrast to the values reported by Lee \& Zhu for Dnmt1 inhibition [12]. Despite the structural similarity of these two enzymes a predictive design of inhibitors targeting both classes of enzymes does not seem possible, which can be turned into an advantage considering that the compounds investigated by us and by Lee show remarkable selectivity for either Dnmt1 or Dnmt3a.

\section{Conclusions}

We have shown that the black tea polyphenols, in particular theaflavin 3, 3'-digallate N6 and thearubigin fraction inhibit Dnmt3a with a physiologically and 
nutritionally relevant $\mathrm{IC}_{50}$ value and therefore identified a novel biological target that is able to rationalize both anti-carcinogenic activity and mental health and performance related activity of black tea.

\section{Methods}

\section{Expression and purification of Dnmt3a-C}

The mouse Dnmt3a C-terminal domain was expressed and purified as described $[29,30]$. The purity of protein was determined on 12\% SDS-PAGE gel stained with colloidal Coomassie Blue (Figure 1). Protein concentration was determined from the absorbance at $280 \mathrm{~nm}$ using an extinction coefficient of $39290 \mathrm{M}^{-1} \mathrm{~cm}^{-1}$.

\section{DNA methyltransferase activity assay}

Kinetics of Dnmt3a-C was analyzed by using a BiotinAvidin methylation kinetics assay basically as described [50] using a biotinylated oligonucleotide substrate and [methyl-3H]AdoMet.

FP3 5'-TTGCACTCTCCTCCCGGAAGTCCCAGCTTC-3' FP3-Bt 5'-Bt-GAAGCTGGGACTTCCGGGAGGAGAGTGCAA-3'; The oligonucleotides were annealed by heating to $86^{\circ} \mathrm{C}$ for some minutes and slowly cooling down to ambient temperature. The methylation reactions were carried out in methylation buffer $[20 \mathrm{mM}$ HEPES pH 7.2, $1 \mathrm{mM}$ EDTA, $50 \mathrm{mM} \mathrm{KCl}, 25 \mathrm{mg} / \mathrm{ml}$ bovine serum albumin (BSA)] at $37^{\circ} \mathrm{C}$, using $1 \mu \mathrm{M}$ substrate DNA, $0.76 \mu \mathrm{M}$ AdoMet and $2.5 \mu \mathrm{M}$ Dnmt3a-C. After the methylation reaction, the oligonucleotides were immobilized at various time points on an avidin-coated microplate. The incorporation of $[3 \mathrm{H}]$ into the DNA was quenched by addition of an excess of unlabeled AdoMet to the binding buffer. Subsequently, unreacted AdoMet was removed by washing five times with PBST containing $0.5 \mathrm{M} \mathrm{NaCl}$. The immobilized DNA was digested with a non-specific endonuclease to release the radioactivity from the microplate. After digestion, $120 \mu \mathrm{l}$ of the reaction mixture were transferred to a fresh microplate and $160 \mu \mathrm{l}$ of Microscint-PS scintillation fluid (Perkin Elmer) was added to each well. Finally, the amount of methyl groups transferred to the DNA and the solution obtained after nucleolytic digestion was quantified by using the TopCount NXT liquid scintillation counter. To determine the initial slope, the data were fitted by linear regression of the initial part of the reaction progress curves.

All the inhibitors were prepared in the DMSO at 5 $\mathrm{mM}$ stock. For the screening purpose $100 \mu \mathrm{M}$ concentrations of the inhibitors were used in the reaction mixture. To detemine the apparent IC50 value for the potential inhibitors, different concentration of the inhibitors were used in the reaction mixture $(10 \mu \mathrm{M}, 25$ $\mu \mathrm{M}, 50 \mu \mathrm{M}, 100 \mu \mathrm{M}, 250 \mu \mathrm{M}, 500 \mu \mathrm{M})$. The different concentrations of the inhibitors were incubated with Dnmt3a protein for $10 \mathrm{~min}$ at room temp. The reaction was started by adding substrate and cofactor and further incubated at $37^{\circ} \mathrm{C}$ for another $10 \mathrm{~min}$ then the reaction was stopped by adding excess unlabelled AdoMet. The DMSO was used as control in each experimental setup to exclude the possible inhibition effect from the DMSO itself. All the inhibitor kinetics was done at duplicate and standard error was calculated for the two experimental values.

\section{Isolation and synthesis of inhibitors}

EGCG N1 and (-)-epigallocatechin (N4), theaflavin (N2), theaflavin-3-gallate (N3), theaflavin 3'-gallate (N5) and theaflavin 3, 3'-digallate (N6) were from black tea obtained using published procedures (Figure 2) [33,51]. Thearubigin fractions (N7 and N8) were obtained from black tea and characterised using published procedures [33,51]. All chlorogenic acid derivatives were obtained by synthesis using published procedures (Figure 2) [52].

\section{Acknowledgements}

The authors thank Jacobs University Bremen for a scholarship to Rakesh Jaiswal. Technical assistance from Ms. Anja Müller is gratefully acknowledged. This work was supported by DFG grant JE 252/6.

\section{Author details}

${ }^{1}$ Chemistry, Jacobs University Bremen, Campus Ring 1, 28759 Bremen, Germany. ${ }^{2}$ Biochemistry, Jacobs University Bremen, Campus Ring 1, 28759 Bremen, Germany. ${ }^{3}$ MoLife program, Jacobs University Bremen, Campus Ring 1, 28759 Bremen, Germany.

\section{Authors' contributions}

$A R, Z T$ and RJ conducted and analyzed the experiments. NK and AJ participated in the design of the study and in data analysis and interpretation and drafted the manuscript. All authors read and approved the final manuscript.

Received: 17 March 2011 Accepted: 21 April 2011

Published: 21 April 2011

\section{References}

1. Poulter S: Daily Mail Online 2008 [http://dailymail.co.uk]

2. Gardner EJ, Ruxton CHS, Leeds AR: Black tea - helpful or harmful? A review of the evidence. European Journal of Clinical Nutrition 2007, 61(1):3-18.

3. Higdon JV, Frei B: Coffee and health: A review of recent human research. Critical Reviews in Food Science and Nutrition 2006, 46(2):101-123.

4. Dorea JG, da Costa THM: Is coffee a functional food? British Journal of Nutrition 2005, 93(6):773-782.

5. Hamer M, Williams ED, Vuononvirta R, Gibson EL, Steptoe A: Association between coffee consumption and markers of inflammation and cardiovascular function during mental stress. Journal of Hypertension 2006, 24(11):2191-2197.

6. Franco R: Coffee and mental health. Atencion Primaria 2009, 41(10):578-581.

7. Hozawa A, Kuriyama S, Nakaya N, Ohmori-Matsuda K, Kakizaki M, Sone T, Nagai M, Sugawara Y, Nitta A, Tomata $Y$, et al: Green tea consumption is associated with lower psychological distress in a general population: the Ohsaki Cohort 2006 Study. American Journal of Clinical Nutrition 2009, 90(5):1390-1396

8. de Mejia EG, Ramirez-Mares MV, Puangpraphant S: Bioactive components of tea: Cancer, inflammation and behavior. Brain Behavior and Immunity 2009, 23(6):721-731.

9. Nurk E, Refsum H, Drevon CA, Tell GS, Nygaard HA, Engedal K, Smith AD: Intake of Flavonoid-Rich Wine, Tea, and Chocolate by Elderly Men and 
Women Is Associated with Better Cognitive Test Performance. Journal of Nutrition 2009, 139(1):120-127.

10. Fang MZ, Chen DP, Yang CS: Dietary polyphenols may affect DNA methylation. Journal of Nutrition 2007, 137(1):223S-228S.

11. Lee WJ, Shim JY, Zhu BT: Mechanisms for the inhibition of DNA methyltransferases by tea catechins and bioflavonoids. Molecular Pharmacology 2005, 68(4):1018-1030.

12. Lee WJ, Zhu BT: Inhibition of DNA methylation by caffeic acid and chlorogenic acid, two common catechol-containing coffee polyphenols. Carcinogenesis 2006, 27(2):269-277.

13. Nandakumar V, Vaid M, Katiyar SK: (-)-Epigallocatechin-3-gallate reactivates silenced tumor suppressor genes, Cip1/p21 and p16INK4a, by reducing DNA methylation and increasing histones acetylation in human skin cancer cells. Carcinogenesis 2011.

14. Klose RJ, Bird AP: Genomic DNA methylation: the mark and its mediators. Trends Biochem Sci 2006, 31(2):89-97.

15. Jurkowska RZ, Jurkowski TP, Jeltsch A: Structure and function of mammalian DNA methyltransferases. Chembiochem 2011, 12(2):206-222.

16. Jeltsch A: Beyond Watson and Crick: DNA methylation and molecular enzymology of DNA methyltransferases. Chembiochem 2002, 3(4):274-293.

17. Jones PA, Baylin SB: The epigenomics of cancer. Cell 2007, 128(4):683-692.

18. Feinberg AP, Tycko B: The history of cancer epigenetics. Nat Rev Cancer 2004, 4(2):143-153.

19. Egger G, Liang GN, Aparicio A, Jones PA: Epigenetics in human disease and prospects for epigenetic therapy. Nature 2004, 429(6990):457-463.

20. Yoo CB, Jones PA: Epigenetic therapy of cancer: past, present and future. Nature Reviews Drug Discovery 2006, 5(1):37-50

21. Gal-Yam EN, Saito Y, Egger G, Jones PA: Cancer epigenetics: modifications, screening, and therapy. Annu Rev Med 2008, 59:267-280.

22. Kelly TK, De Carvalho DD, Jones PA: Epigenetic modifications as therapeutic targets. Nat Biotechnol 2010, 28(10):1069-1078.

23. Levenson JM, Sweatt JD: Epigenetic mechanisms: a common theme in vertebrate and invertebrate memory formation. Cellular and Molecular Life Sciences 2006, 63(9):1009-1016.

24. Wu H, Coskun V, Tao J, Xie W, Ge W, Yoshikawa K, Li E, Zhang Y, Sun YE: Dnmt3a-dependent nonpromoter DNA methylation facilitates transcription of neurogenic genes. Science 2010, 329(5990):444-448.

25. Feng J, Zhou Y, Campbell SL, Le T, Li E, Sweatt JD, Silva AJ, Fan G: Dnmt1 and Dnmt3a maintain DNA methylation and regulate synaptic function in adult forebrain neurons. Nat Neurosci 2010, 13(4):423-430.

26. LaPlant Q, Vialou V, Covington HE, Dumitriu D, Feng J, Warren BL, Maze I, Dietz DM, Watts EL, Iniguez SD, et al: Dnmt3a regulates emotional behavior and spine plasticity in the nucleus accumbens. Nat Neurosci 2010, 13(9):1137-1143.

27. Weaver ICG, Cervoni N, Champagne FA, D'Alessio AC, Sharma S, Seckl JR, Dymov S, Szyf M, Meaney MJ: Epigenetic programming by maternal behavior. Nature Neuroscience 2004, 7(8):847-854.

28. Feng J, Fan G: The role of DNA methylation in the central nervous system and neuropsychiatric disorders. Int Rev Neurobiol 2009, 89:67-84.

29. Gowher $H$, Jeltsch A: Molecular enzymology of the catalytic domains of the Dnmt3a and Dnmt3b DNA methyltransferases. J Biol Chem 2002, 277(23):20409-20414

30. Jurkowska RZ, Anspach N, Urbanke C, Jia D, Reinhardt R, Nellen W, Cheng $X$, Jeltsch A: Formation of nucleoprotein filaments by mammalian DNA methyltransferase Dnmt3a in complex with regulator Dnmt3L. Nucleic Acids Res 2008, 36(21):6656-6663.

31. Drynan JW, Clifford MN, Obuchowicz J, Kuhnert N: The chemistry of low molecular weight black tea polyphenols. Natural Product Reports 2010, 27(3):417-462.

32. Roberts EAH, Catrwright RA, Oldschool M: I Sci Food Agric 1959, 8:72-80.

33. Kuhnert N, Drynan JW, Obuchowicz J, Clifford MN, Witt M: Mass spectrometric characterization of black tea thearubigins leading to an oxidative cascade hypothesis for thearubigin formation. Rapid Communications in Mass Spectrometry 2010, 24(23):3387-3404.

34. Kuhnert $\mathrm{N}$ : Unraveling the structure of the black tea thearubigins. Archives of Biochemistry and Biophysics 2010, 501(1):37-51.

35. Roberts EAH, Myers M: J Sci Food Agric 1959, 10:167-179.

36. Clifford MN: Chlorogenic acids and other cinnamates - nature, occurrence and dietary burden. Journal of the Science of Food and Agriculture 1999, 79(3):362-372.
37. Clifford MN, Johnston KL, Knight S, Kuhnert N: Hierarchical scheme for LCMSn identification of chlorogenic acids. Journal of Agricultural and Food Chemistry 2003, 51(10):2900-2911.

38. Clifford MN, Knight S, Surucu B, Kuhnert N: Characterization by LC-MSn of four new classes of chlorogenic acids in green coffee beans: Dimethoxycinnamoylquinic acids, diferuloylquinic acids, caffeoyldimethoxycinnamoylquinic acids, and feruloyldimethoxycinnamoylquinic acids. Journal of Agricultural and Food Chemistry 2006, 54(6):1957-1969.

39. Jaiswal R, Patras MA, Eravuchira PJ, Kuhnert N: Profile and Characterization of the Chlorogenic Acids in Green Robusta Coffee Beans by LC-MSn: Identification of Seven New Classes of Compounds. Journal of Agricultural and Food Chemistry 2010, 58(15):8722-8737.

40. Jaiswal R, Sovdat T, Vivan F, Kuhnert N: Profiling and Characterization by LC-MSn of the Chlorogenic Acids and Hydroxycinnamoylshikimate Esters in Mate (llex paraguariensis). Journal of Agricultural and Food Chemistry 2010, 58(9):5471-5484.

41. Yokochi T, Robertson KD: Dimethyl sulfoxide stimulates the catalytic activity of de novo DNA methyltransferase 3a (Dnmt3a) in vitro. Bioorg Chem 2004, 32(4):234-243.

42. Lin YL, Tsai SH, Lin-Shiau SY, Ho CT, Lin JK: Theaflavin-3,3 '-digallate from black tea blocks the nitric oxide synthase by down-regulating the activation of NF-kappa B in macrophages. European Journal of Pharmacology 1999, 367(2-3):379-388.

43. Bhattacharya U, Halder B, Mukhopadhyay S, Giri AK: Role of oxidationtriggered activation of JNK and p38 MAPK in black tea polyphenols induced apoptotic death of A375 cells. Cancer Science 2009, 100(10):1971-1978.

44. Jochmann N, Lorenz M, von Krosigk A, Martus P, Bohm V, Baumann G, Stangl K, Stangl V: The efficacy of black tea in ameliorating endothelial function is equivalent to that of green tea. British Journal of Nutrition 2008, 99(4):863-868.

45. Lorenz M, Urban J, Engelhardt U, Baumann G, Stangl K, Stangl V: Green and black tea are equally potent stimuli of NO production and vasodilation: new insights into tea ingredients involved. Basic Research in Cardiology 2009, 104(1):100-110.

46. Vermeer MA, Mulder TP, Molhuizen HO: Theaflavins from black tea, especially theaflavin-3-gallate, reduce the incorporation of cholesterol into mixed micelles. J Agric Food Chem 2008, 56(24):12031-12036.

47. Henning SM, Aronson W, Niu YT, Conde F, Lee NH, Seeram NP, Lee RP, Lu JX, Harris DM, Moro A, et al: Tea polyphenols and theaflavins are present in prostate tissue of humans and mice after green and black tea consumption. Journal of Nutrition 2006, 136(7):1839-1843.

48. Vauzour D, Rendeiro C, Corona G, Williams C, Spencer JEP: Polyphenol commun 2010, 1:70-71.

49. Müller-Harvey I, Botchway S, Feucht W, Polster J, Burgos P, Parker A: Planta Medica 2010, 76:1167.

50. Roth $M$, Jeltsch A: Biotin-avidin microplate assay for the quantitative analysis of enzymatic methylation of DNA by DNA methyltransferases. Biological Chemistry 2000, 381(3):269-272.

51. Kuhnert N, Clifford MN, Muller A: Oxidative cascade reactions yielding polyhydroxy-theaflavins and theacitrins in the formation of black tea thearubigins: Evidence by tandem LC-MS. Food \& Function 2010, 1(2):180-199.

52. Kuhnert N, Jaiswal R, Eravuchira P, El-Abassy RM, von der Kammer B, Materny A: Scope and limitations of principal component analysis of high resolution LC-TOF-MS data: the analysis of the chlorogenic acid fraction in green coffee beans as a case study. Analytical Methods 2011, 3(1):144-155.

doi:10.1186/1471-2091-12-16

Cite this article as: Rajavelu et al:: The inhibition of the mammalian DNA methyltransferase $3 a(D n m t 3 a)$ by dietary black tea and coffee polyphenols. BMC Biochemistry 2011 12:16. 